\title{
LOS MORISCOS DE CASTILLA LA VIEJA, ¿UNA IDENTIDAD EN PROCESO DE DISOLUCIÓN?
}

\author{
Serafin de Tapia*
}

Creo conveniente dejar establecidos dos principos básicos: primero, que es imposible concebir a los moriscos del conjunto del Reino como un todo homogéneo en el espacio y estable en el tiempo y, segundo, que el tipo de fuentes utilizadas para estudiar la minoría es determinante: todas son parciales y si sólo se emplea una de ellas la visión obtenida será no sólo incompleta sino sesgada. Aunque hoy ya parezca que son obviedades, conviene seguir insistiendo en ellas.

El objeto de atención de la páginas siguientes no serán los moriscos granadinos que llegaron a Castilla en 1570 sino los "antiguos" o "convertidos" -es decir, los descendientes de los mudéjares locales-y la percepción que, tanto ellos mismos como el conjunto de la mayoría cristiano-vieja, tenían de su identidad como grupo. El ámbito cronológico de este artículo discurrirá desde mediados del siglo XVI hasta el momento de la expulsión, a fin de observar a unos moriscos suficientemente alejados en el tiempo de su anterior status de musulmanes "oficiales".

En 1991 F. Márquez Villanueva publica El problema morisco (desde otras laderas) y en 1993 ve la luz Los moriscos (desde su misma orilla) de A. Galmés de Fuentes ${ }^{1}$. La correspondencia entre ambos subtítulos es evidente y responde al deseo del profesor Galmés de contestar a un aspecto sustancial de las tesis sostenidas desde hace tiempo por Márquez Villanueva.

Este último es, probablemente, el autor que más lejos se atreve a llegar dentro de la teoría "asimilacionista", es decir, la que sostiene que existía un proceso imparable de acercamiento de los moriscos hacia la cultura cristiana

Universidad de Salamanca.

1. F. Márquez Villanueva, El problema morisco (desde otras laderas), ed. Libertarias/Prodhufi, Madrid, 1991. A. GAlmÉs DE Fuentes, Los moriscos (desde su misma orilla), Instituto Egipcio de Estudios Islámicos, Madrid, 1993. 
y que su integración total fue traumáticamente cortada por la decisión real de su expulsión.

Alvaro Galmés mantiene, por el contrario, que fue durante las últimas décadas de la permanencia cuando los moriscos, al comprobar que continuaban siendo rechazados socialmente por la mayoría cristiano-vieja, reaccionaron reavivando y radicalizando su fe islámica.

Estos son, esquemáticamente, los términos de la polémica.

Yo creo que ambos sostienen posiciones maximalistas porque en esta cuestión sus planteamientos son adialécticos, casi mecanicistas: Márquez considera que la "integración social" conduce inexorablemente a la asimilación cultural. Y Galmés cree que la cultura islámica puede comportarse como una variable independiente.

Es probable que ambos autores hayan llegado a posiciones tan extremadas a causa de haber practicado una especie de monocultivo de fuentes de información. Por otra parte, me parece cuestionable la rotundidad de sus tomas de posición y su alto grado de generalización.

$\mathrm{El}$ análisis que presento corresponde a mi perfil profesional de historiador de lo social -no soy arabista ni islamólogo-. Admito, por tanto, como lógico que haya otras perspectivas desde las que se pueda llegar a interpretaciones distintas e incluso contrarias.

Mi punto de partida es que "integración social" y "asimilación cultural" o aculturación son dos fenómenos diferentes. No hay duda. La doctrina y la práctica de la "taquiyya" o disimulo lo demuestra. Sin embargo, ambas son situaciones dinámicas, es decir, son procesos que admiten diferentes intensidades. Aceptando que "integración social" y "asimilación cultural" son fenómenos muy relacionados e incluso con cierto grado de interdependencia, yo no me atrevo a establecer una relación directa y mecánica entre el proceso de la integración social con la mayoría cristiana y el de la pérdida de la identidad islámica.

Y por otra parte $¿$ cabe aceptar como prueba evidente de que el conjunto de la colectividad morisca se mantenía fiel al Islam el hecho de que existiera cierta literatura aljamiada? ¿No podría tratarse del intento de determinados individuos o colectivos de utilizar el factor religioso para preservar la personalidad del grupo? ¿Hay testimonios documentales suficientes de que la mayoría de los moriscos rechazaran la integración en la sociedad mayoritaria apostando por el mantenimiento de la fe de sus mayores?

Con la pretensión de llenar de contenido las anteriores reflexiones, he buscado testimonios concretos que abonen las distintas tomas de posición: unos que indiquen la voluntad de los moriscos -colectiva o individualmentede mantener la propia identidad y otros que expresen el deseo de integrarse 
con la mayoría cristiana. El distinto grado de explicitación, de verosimilitud de cada tipo de testimonio nos ayudará a despejar la contradicción planteada.

Uno de los factores que más contribuye a conformar la identidad de cualquier minoría es la consideración que esta minoría merece al grupo mayoritario: si se les acepta como ciudadanos de pleno derecho o se les soporta como un grupo de impuros, de excluídos, de indeseables ${ }^{2}$. Por ello también he buscado testimonios de aceptación o de rechazo de los cristianos hacia los moriscos.

Tal como se indica en el título de este trabajo, el escenario de observación será el referido a los descendientes de los mudéjares de Castilla la Vieja. Dentro de este amplio territorio había una gran diversidad entre unas comunidades moriscas y otras: los de Segovia eran pocos y de economía modesta, los de Arévalo eran numerosos (109 familias en 1565) y poseían muchas tierras de pan llevar, los de Valladolid también eran abundantes (al menos 155 familias en 1565) y con no pocas viñas, aunque había muchos jornaleros entre ellos $^{3}$. No obstante, la mayoría de los testimonios se referirán a la comunidad morisca de la ciudad de Avila, la más numerosa de la región (206familias en 1565) y la que cuenta con documentación más rica y variada ${ }^{4}$. Las fuentes empleadas son, básicamente, las que se refieren al conjunto de los ciudadanos (Protocolos Notariales, Procesos Judiciales en primera instancia, Vecindarios fiscales, Actas del Ayuntamiento y del Cabildo Catedralicio, Documentación Parroquial...); tal documentación sólo es útil -a los efectos de este trabajo- en la medida que se haya podido establecer una identificación étnica segura de los individuos que aparecen en ella, y con el uso de tal documentación ordinaria se pretende sorprender la cotidianidad de las relaciones existentes entre los cristianos viejos y sus instituciones y los "convertidos". También se han tenido en cuenta las fuentes inquisitoriales conservadas 5 .

2. R. CARRASCO, «Le refus d'assimilation des Morisques: aspects politiques et culturels d'après les sources inquisitoriales», en Varios, Les morisques et leur temps, CNRS, Paris, 1983, pp. 169-212.

3. S. DE TAPIA, «Una minoría urbana mal conocida: los moriscos 'convertidos' de Castilla la Vieja», en el libro colectivo: 1490. En el umbral de la modernidad, Generalitat Valenciana, Valencia, 1994, pp. 447-473.

4. S. DE TAPIA, La comunidad morisca de Avila, Universidad de Salamanca, Salamanca, 1991.

5. Lamentablemente gran parte de la documentación del Santo Oficio correspondiente al distrito de Valladolid en el siglo XVI se ha perdido, no conservándose los Procesos ni las Relaciones de Causas anteriores a 1622. Las series documentales conservadas y empleadas han sido la de los libros de Cartas, Provisiones y Despachos del Consejo de la Suprema a los Tribunales (una especie de Registro de Entrada y Registro de Salida de la correspondencia entre la Suprema y las inquisiciones territoriales) y la de Cartas al Consejo, Expedientes y Memoriales (copia de la correspondencia enviada desde la Inquisición de Valladolid al Consejo de la Suprema). Las Cartas, Provisiones... se hallan en el Archivo Histórico Nacional (AHN), Inquisición, libros 572 a 577, y las Cartas al Consejo... en los legajos 3.189 a 3.205. 


\section{TESTIMONIOS QUE INDICAN LA VOLUNTAD DE MANTENER} LA PROPIA IDENTIDAD

\section{TESTIMONIOS COLECTIVOS}

1. Muy frecuentemente los "convertidos" comparecían colegiadamente ante las instituciones indicando su calidad de descendientes de los "nuevamente convertidos de moros". Cuando esto ocurría la práctica totalidad de los cabezas de familia previamente había otorgado poder notarial a alguno de ellos para que les representara en conjunto ${ }^{6}$. Tal.ocurría en las diversas negociaciones habidas entre los moriscos de las ciudades castellanas y el Santo Oficio, bien para lograr Edictos de Gracia, bien para pactar el pago del "situado" ${ }^{\prime 7}$. O cuando se reclamaba algo al Concejo ${ }^{8}$.

2. Existieron algunas compañías comerciales compuestas exclusivamente por socios moriscos que eran utilizadas, además de para los negocios al uso, para mantener una red de contactos entre los moriscos de varios lugares de la Corona. En otro lugar he descrito la que hacia 1553-1573 desarrolla su actividad entre Medina del Campo, Medina de Rioseco, Villalón, Arévalo y Valencia ${ }^{9}$.

3. Había redes destinadas a mantener contactos con moriscos que habían marchado a tierras del Islam y a llevar allá a moriscos castellanos que deseaban "salir deste captiverio" y "vivir en livertad y para no estar sufriendo tantas molestias como los herejes de los inquisidores les hacían cada día". Esta red estaba compuesta de personas que vivían en la clandestinidad y de arrieros de larga distancia ${ }^{10}$. Un apoyo importante en estas redes lo desempeñaban los mesones regentados por moriscos, hasta el punto de que en

6. Así aconteció en 1549 en Avila cuando los moriscos recurrieron alguna de las disposiciones del inquisidor Vaca (Archivo Histórico Provincial de Avila -AHPAv-, Protocolo -Pr.- 409, fols. 79-86v y 124-124v). Esta frecuente actuación colectiva podría incluso ser interpretada como indicio de una cierta pervivencia del viejo vínculo de la aljama, "el elemento nuclear de la comunidad morisca española" (M. DE EPALZA, Los moriscos españoles antes y desputés de la expulsión, Mapfre, Madrid, 1992, p. 102).

7. Por ejemplo, en las negociaciones del Edicto de Gracia de 1558 y del "situado" de ese mismo año participan una serie de representantes de los convertidos del distrito inquisitorial de Valladolid: Diego Monje (Ávila), Grabiel Vori (Arévalo), Lope de Castañeda y Pedro Belázquez (Medina del Campo), Francisco Amador (Avila), Anbrosio de Ençinas (Arévalo), Gerónimo de Samaniego (Segovia), Márquez Vorrejón (Palencia) y Lope Morejón (Valladolid) (AHN, Inquisición, libro 1254, fols. 270-273 y leg. 2110, exp. 2).

8. En 1596 los convertidos de Avila reclaman su derecho a ser alistados en la milicia (AHPAv, Sección A, caja 656, s.f.).

9. S. DE TAPIA, «Las redes comerciales de los moriscos de Castila la Vieja: un vehículo para sus 'complicidades'», Studia Historica. Historia Moderna, Salamanca, XI, 1993, pp. 231-243.

10. Ibídem, pp. 237-238. 
1568 los inquisidores de Valladolid propusieron que se prohibiese a los cristianos nuevos dedicarse a estas labores ${ }^{11}$.

4. Se comprueba que la solidaridad del grupo hacía posible encontar refugio fuera de la propia ciudad cuando se necesitaba. He detectado colonias de moriscos castellanos en Calatayud, Torrellas, Valencia.... y personas aisladas en Segorbe, Granada... que conservaban sus contactos con los correligionarios de la Meseta ${ }^{12}$.

5. En algunos lugares de Castilla los "convertidos" se exiliaron en 1610 , antes de que se hubiera dictado la orden de expulsión expresamente dirigida a ellos; tal ocurrió con los de Valladolid y Arévalo. En cambio otros, como los de Avila, hicieron todo tipo de gestiones para ser excluídos de aquella orden ${ }^{13}$.

\section{TESTIMONIOS INDIVIDUALES}

1. Aunque en estas tierras la actividad inquisitorial sobre los moriscos no fue muy significada, también hubo casos de criptoislamismo: entre 1520 y 1564 sé de 23 procesados y entre 1570 y 1609 fueron 163 en el conjunto del distrito de Valladolid, mitad "convertidos" y mitad granadinos. Naturalmente, había núcleos donde la Inquisición actuaba con más frecuencia (Arévalo, Olmedo...) que en otros (Avila, Salamanca...) ${ }^{14}$.

2. No he encontrado referencias claras a la existencia de moriscos castellanos. En cambio, dos de los abulenses que lograron permanecer después de la expulsión por tener informes de ser buenos cristianos, no tardaron en ordenarse de sacerdotes ${ }^{15}$.

11. Un inquisidor escribe desde Arévalo a la Suprema proponiendo que "ninguna persona destos conbertidos fuese ni pudiese ser mesonero porque los arrieros que vienen dellos, así del Andaluçía como los hombres que pasan allende a estas partes, se andan entre ellos como entre sus parientes y allí son encubiertos por muchos días" (AHN, Inq, leg. 3.189, exp. 120).

12. S. DE TAPIA, «Las redes comerciales...».

13. S. DE TAPIA, La comunidad..., pp. 350-351.

14. Ibidem, pp. 251-258.

15. Dudosa credibilidad hay que dar a lo que se dice en un informe elaborado por espías que la Corona infiltró entre los moriscos castellanos en 1565: que el líder de los moriscos de Segovia, el carpintero Luis Caniego, tiene muchos parientes en el pueblo de Los Casares, cerca de Aranda de Duero (Burgos), y que "los clérigos que los confiesan y administran los sacramentos [a los moriscos] son tan moros como ellos" (AHN, Inq. leg. 3.205-2). En 1590 hay una fugaz referencia a "Porlillo, clérigo", hijo de una acomodada familia morisca; aparece junto a su padre siendo testigo del matrimonio de dos granadinos (Arch. Parroq. Santo Domingo, Avila, Libro de Casados, fol. 166, 11-XI-1590); el tal Porlillo debió marcharse de Avila pues no vuelve a haber rastro de él. Respecto a los piadosos hermanos Navas, que terminaron siendo clérigos: AHPAv, Actas Ayuntam. libro 32, fol. 146 v (16-XII-1616). Ver S. DE TAPIA, La comunidad..., p. 385. 
3. Entre la documentación inquisitorial abundan los ejemplos que denotan que los moriscos tenían total desinterés -cuando no desprecio- por las ceremonias cristianas: en 1564 los inquisidores reprochan a los de Valladolid que "los días de domingo no váis a misa ni a los sermones... antes os váis a unas viñas e hacéis labor...", echándoles en cara que en 60 años no hubieran aprendido ni una sola oración ${ }^{16}$. En 1565 varias moriscas de Segovia, hablando entre ellas, dicen que "se habían de confesar y comulgar... porque los herejes de los descreídos cristianos no sospechasen dellas mal", y otra añadía: "también traigo yo rosario y crucifijo en él por cumplir con estos descreídos, riéndose todas a manera de escarnio"17.

4. A pesar de las recomendaciones de las autoridades cristianas para que se produjeran uniones matrimoniales entre moriscos y cristianos viejos, estos matrimonios mixtos fueron muy escasos. Incluso en Avila, la ciudad donde mejores relaciones había entre unos y otros, de los 329 matrimonios de moriscos detectados sólo 11 (el 3,3 por ciento) fueron mixtos ${ }^{18}$. Estoy seguro de que en los demás lugares esta práctica fue aún menos frecuente.

5. La persistencia de las viejas morerías, que agrupaban a la mayor parte de los moriscos incluso en las vísperas de la expulsión, puede ser interpretada como indicio del deseo de seguir formando parte de un grupo humano diferente al de la mayoría o, en todo caso, del temor a que los cristianos viejos observaran su vida doméstica, todavía con muchas costumbres heredadas (en el comer, la higiene, las fiestas familiares, etc.) susceptibles de ser interpretadas como rituales islámicos por la Inquisición ${ }^{19}$.

Llegados a este punto, conviene advertir que las referencias que siguen se refieren a los moriscos de la ciudad de Avila. Por ello, sólo si proceden de otros lugares se indicaría esta circunstancia.

16. AHN, Inq. libro 1254, fol. 235.

17. AHN, Inq. leg. 3205-2.

18. S. DE TAPIA, La comunidad..., epígrafe "La endogamia morisca", pp. 174-176.

19. Sobre el mantenimiento de la concentración de la población morisca en los barrios que en el pasado fueron morería ver S. DE TAPIA, La comunidad..., epígrafe "Distribución espacial urbana", pp. 154-157. Y acerca de las relaciones de vecindad entre moriscos y cristianos viejos, aparte de lo escrito sobre este asunto por L. CARDAILLAC (Moriscos y cristianos. Un enfrentamiento polémico, FCE, Madrid, 1979, pp. 21-31), resulta elocuente la respuesta dada por un párroco de Arévalo a los inquisidores en 1583, en el marco de una investigación de una supuesta marcha clandestina de moriscos castellanos hacia Aragón y Valencia, camino de Argel; dice el clérigo: "en este particular yo lo inquiriré con gran recato i diligencia; el medio por donde lo sabré es que io tengo un feligrés cristiano viejo y es vecino de muchos dellos i me dirá su trato porque es çeloso de las cosas de Dios i los trata mucho" (AHN, Inq. leg. 2.111, pieza 3). 


\section{TESTIMONIOS QUE INDICAN LA VOLUNTAD \\ DE NO DISTINGUIRSE DE LOS CRISTIANOS VIEJOS}

\section{TESTIMONIOS COLECTIVOS}

1. En 1596 pleitean con el Concejo de Avila a fin de que se aliste en la milicia que recluta el rey a los "convertidos" varones de 18 a 44 años. Transcribo un fragmento donde expresan nítidamente en qué fundamentan sus pretensiones: "... y en no los alistar es poner en ellos alguna nota y flaqueça de que no seruirán a Su Magestad como quales quier otros de mayor y menor estado; y ellos todos an sido y son y se diçen y llaman christianos viejos y como tales, en púvlico y en secreto, an traydo e traen sus armas que no se les a proyvido ni puede proyvir conforme a leyes destos Reynos, no exçediendo de la forma de ellas, y como las an traydo y traen los demás christianos viejos desta çiudad; y an sido e son admitidos en todas las llegas y juntas do se juntan los vecinos desta çiudad, hora por quadrillas hora en otra manera; y an sido y son admitidos a todos los offiçios de honrra desta çiudad adonde an sido admitidos los demás cristianos viejos desta çiudad y se a hecho conffiança dellos como de los demás. $\mathrm{Y}$ an sido yligidos por deputados y aconpañados en esta çiudad y an sido fieles y alcaldes de la hermandad de ella. Y Su Magestad les a dado y da título de sus escriuanos y de el número desta çiudad" ${ }^{\prime 20}$. El año 1609, en una circunstancia similar, reiteran su reclamación.

2. Los "convertidos" no pierden ocasión de dejar claro ante las autoridades que ellos son distintos de los granadinos que habían llegado a Castilla en 1570. Así, en el pleito antes referido alegan que ellos son "desçendientes de convertidos viejos y sus antepassados son auidos e tenidos por cristianos viejos por serlo ellos e sus padres y aguelos y antepassados y para ninguna cosa en esta çiudad auido diferençia de vnos çiudadanos a otros como quiera que sean vecinos desta çiudad y si algunos se pueden deçir christianos nuevos serán los que están alistados en esta çiudad de el Reyno de Granada, que della y de el dicho rreyno fueron traydos a esta çiudad, que no pueden traer ni traen armas ni hasta agora an sido admitidos a los offiçios" (el subrayado es mío). Esta percepción de ser diferentes de los granadinos se materializaba en la escasez de matrimonios entre éstos y los descendientes de los mudéjares castellanos; tales uniones eran aún mas raras que las habidas con cristianos viejos.

3. En la segunda mitad del siglo XVI se produjo un significativo cambio en el destino geográfico de las relaciones comerciales de los convertidos. Si hasta 1558 predominaron los intercambios con las zonas más islamizadas de la Corona (Granada, Valencia...), a partir de entonces se prefirió comerciar

20. AHPAv, Audiencia, caja 656 , s.f. 
con los lugares económicamente más dinámicos (Sevilla, Lisboa, Valladolid...), aunque en éstos la presencia de moriscos fuera mucho menor ${ }^{21}$.

4. Analizando las relaciones económicas de los moriscos desde el punto de vista étnico, se observa que desde 1503 hasta 1553 el número de las operaciones entre los propios moriscos va creciendo (llegan a ser el $38 \%$ del total) y a partir de entonces van disminuyendo (en 1603 sólo significan el $22 \%)^{22}$.

5. Cuando se hacen públicos los bandos de expulsión, los convertidos de la ciudad de Avila presentan recursos ante diversas autoridades locales y nacionales pretendiendo que a ellos no les afectan aquellas órdenes ${ }^{23}$.

\section{TESTIMONIOS INDIVIDUALES}

1. En 1585 un morisco abulense explica cómo su padre participó en una fiesta que un noble local organizó en 1535 para celebrar la toma de la Goleta por Carlos V. En el desfile el convertido salió como alférez, portando la bandera "vestido de terciopelo negro todo él de pies a cabeza"24.

2. Hubo moriscos (he localizado 4 en Avila) alistados voluntariamente en las guerras de Italia y Malta, en las del norte de Africa e incluso en la guerra de Granada. De uno de ellos, que era sargento y que participó en el socoro de Orán y Mazalquivir (año 1563), se dice que "mató mucha cantidad de moros y turcos por su persona" 25 .

3. Algunos comportamientos en la vida privada de determinados moriscos resultan chocantes en quienes son calificados como criptomusulmanes:

- María de Cuéllar se fue a vivir a un convento de monjas mientras se resolvía el pleito de su divorcio con un rico mercader también morisco $^{26}$.

- Una pareja se prometió en matrimonio en una habitación de su casa delante de una imagen de la Virgen y con dos testigos ${ }^{27}$.

- Isabel de la Serna, esposa de otro acaudalado mercader morisco, establece poco antes de exiliarse que se sigan diciendo 4 misas perpetuas cada año en su parroquia ${ }^{28}$.

21. S. DE TAPIA, La comunidad..., epígrafes "Análisis espacial de las relaciones económicas" y "La movilidad laboral de los convertidos", pp. 206-212 y 316-326 respectivamente.

22. Ibídem, epígrafe "Relaciones económicas entre las dos etnias", pp. 194-196.

23. AGS, Estado, leg. 235.

24. AHPAv, Audiencia, caja 573, s.f.

25. Ibídem, caja 656 , s.f.

26. AHPAv, Pr. 177, s.f. (12-11-1605).

27. AHPAv, Audiencia, caja 540, s.f. (año 1606). El rechazo a las imágenes por parte de los moriscos islamizados era habitual (L. CARDAILLAC, op. cit., pp. 121 y 301-303).

28. AHPAv, Pr. 553 fol. 56 . 
4. Aunque la mayoría de los moriscos prefería habitar en el barrio tradicionalmente ocupado por sus predecesores, cada vez es más habitual ver a convertidos -sobre todo si son acomodados o tienen negocios- viviendo en las zonas céntricas de la ciudad ${ }^{29}$.

5. Hay alguna declaración explícita de ser cristianos viejos por parte de individuos inconfundiblemente moriscos. Tal es el caso del doctor Alonso de Valdivieso, médico, quien en julio de 1612 pretende "no ser de los comprendidos en los bandos de expulsión, por ser cristiano viejo y descendiente de tales y... que, si en razón de apremialle y compelelle a ello, saliere dellos sea visto ser por redimir vejaciones, prisiones, costas y gastos que se le hacen y no por ser de los comprehendidos en los bandos" ${ }^{\prime 30}$.

6. Durante los dos o tres meses que precedieron a la expulsión en julio de 1611, varias familias bautizaron a sus hijos. No cabe interpretar estos actos como afán de grangearse ante el obispo fama de buenos cristianos para evitar el éxodo pues por aquellas fechas ya se había hecho público que, incluso los que hubieran obtenido informes favorables del obispo, deberían salir del reino ${ }^{31}$.

7. El cronista Gil González Dávila, buen conocedor del episodio de la expulsión, relata cómo algunos moriscos abulenses sufrieron martirios al llegar a África ${ }^{32}$. En todo caso este testimonio debe ser tomado con prevención pues lo que González Dávila califica como martirios pudiera perfectamente tratarse de episodios de rapiña similares a los producidos en aquellos momentos con otros grupos moriscos ${ }^{33}$.

\section{TESTIMONIOS DE RECHAZO HACIA LOS MORISCOS POR PARTE DE LOS CRISTIANOS VIEJOS}

\section{TESTIMONIOS COLECTIVOS}

1. Los moriscos recibieron sistemáticamente por parte de las oligarquías urbanas pecheras un trato fiscal muy discriminatorio respecto al resto de los

29. S. DE TAPIA, La comunidad..., epígrafe "Distribución espacial urbana", pp. 154-157. En 1596 el regidor Sancho Cimbrón dice de los convertidos que "andan muy apartados y divididos de los que nuevamente han venido del Reino de Granada..." y de los granadinos, que "han menester mucho tiempo para asemejarse a los convertidos" (AHPAv, Audiencia, caja 656, s.f.).

30. AHPAv, Pr. 742, fol. 932. Naturalmente, éste no es el único caso que conozco; otro es el de una morisca abulense que se ha trasladado a vivir a Gandía -Isabel de la Rúa- y que desea se realicen probanzas para demostrar que "sus antepasados son cristianos viejos y limpios de toda mala rraza"; significativamente los cinco testimonios -todos favorables- pertenecen a otros tantos convertidos (AHPAv, Pr. 750, s.f. 21-XI-1603).

31. S. DE TAPIA, La comunidad..., epígrafe "Los preparativos de la marcha", pp. 355-356 y 380.

32. Theatro Eclesiástico de la ciudad e iglesia catedral de Avila, Madrid, 1645, pp. 197-198.

33. A. Domínguez Ortiz y B. Vincent, Historia de los moriscos Revista de Occidente, Madrid, 1979, pp. 233 y 237. 
pecheros. Aunque ninguna norma escrita lo establecía, cada morisco contribuía de manera aproximada con el doble de lo aportado por los cristianos viejos; esto en circunstancias normales, porque si nos atenemos a los momentos en que la tensión nacional o internacional (p.e. en torno a la batalla de Lepanto) se acentuaba, se comprueba cómo entonces la presión económica era aún mayor. La fiscalidad discriminatoria, por tanto, era no sólo un mecanismo de exacción económica sino también una forma de represión y demostración de dominio político ${ }^{34}$.

2. En 1558 se acordó entre los convertidos de la región y la Inquisición de Valladolid que, a cambio de 400.000 maravedíes al año, el Santo Oficio sería menos riguroso y además no confiscaría los bienes de los condenados. La comunidad de Avila aportaba $102.000 \mathrm{mrs}$. y la de Arévalo $108.000 \mathrm{mrs}^{35}$.

3. Cuando en la ciudad de Avila existía urgente necesidad de dinero el Concejo reclamaba préstamos obligatorios de determinados ciudadanos. Pues bien, en todas las ocasiones el peso mayor recaía sobre los convertidos ricos $^{36}$.

4. Inicialmente se excluye a los moriscos castellanos de formar parte de la milicia reclutada en 1596 y naturalmente en la de $1609^{37}$.

5. En 1571 el Concejo de Avila se opondrá a la pretensión de un convertido de ocupar el cargo de "fiel mero ejecutor" que le otorgaría voz y voto en esta institución. Habría que resaltar que tal petición denota el alto nivel de autoestima de los moriscos abulenses, máxime si se tiene en cuenta que ni un solo pechero ocupaba cargo alguno en tan oligárquico Concejo ${ }^{38}$.

\section{TESTIMONIOS INDIVIDUALES}

1. Esporádicamente los expedientes de la sección Papeles Judiciales del Archivo Histórico Provincial de Avila se hacen eco de querellas presentadas por insultos dirigidos a moriscos con ocasión de riñas y peleas entre individuos de la comunidad morisca y gentes del pueblo: "perro puto moro", "bellaco morisco", "moriscos sebosos"... eran los más comunes 39 .

2. Algunos cristianos viejos se resistían a someterse a la autoridad de los moriscos, como aquel modesto ganadero rural que no quiere reconocer

34. S. DE TAPIA, «La opresión fiscal de la minoría morisca en las ciudades castellanas. El caso de la ciudad de Ávila», Studia Historica. Historia Moderna, Salamanca, IV, 1986, pp. 17-49.

35. S. DE TAPIA, La comunidad..., epígrafe "El 'situado' de 1558: la Inquisición opta por la exacción económica de los moriscos", pp. 241-251.

36. Ibidem, p. 283.

37. AHPAv, Audiencia, caja 656 y Pr. 657, fol. 790 .

38. AHPAv, Actas Consistoriales, libro 15, fol. 78 (año 1571).

39. AHPAv, Pr. 418, fol. 376 ss.; ib. Audiencia, caja 1.068 y caja 1.071. 
como alcalde de la Mesta al acaudalado ganadero convertido Diego Monje el Cuervo $^{40}$.

\section{TESTIMONIOS DE ACEPTACIÓN POR PARTE DE LOS CRISTIANOS}

\section{COLECTIVOS}

1. Aunque los párrocos y los funcionarios municipales abulenses distinguían perfectamente a los cristianos viejos de los moriscos (y, dentro de éstos, a los convertidos de los granadinos), se permitió a los descendientes de los mudéjares desarrollar funciones y ocupar empleos de relevancia social tales como:

- Padrinos en los bautizos.

- Mayordomos de las parroquias del barrio de la morería.

- Alcaldes de la Santa Hermandad.

- Correos oficiales ("ordinarios").

- Escribanos públicos.

- Veedores de diversos oficios: caldereros, carpinteros, rejeros, cereros...

- Diputados de las cuadrillas (distritos fiscales) donde ellos vivían preferentemente.

- Mayordomos de la alhóndiga (donde se guardaban las reservas de trigo y también las escasas armas del Concejo).

- Médicos del Ayuntamiento.

- Abastecedores de diversos productos (carne, velas...).

- Prestamistas de nobles.

- Mercaderes-empresarios que adelantan capital y materia prima a los fabricadores de paños.

- Recaudadores de impuestos ${ }^{41}$.

2. Había familias muy bien consideradas en la ciudad. Por ejemplo, en 1549 el Santo Oficio impuso elevadas multas a numerosos moriscos, entre

40. AHPAv, Audiencia, caja 561 (año 1579). En este caso se comprueba la afirmación de L. Cardaillac de que la lógica de la exclusión se apoya no sólo en argumentos religiosos sino también en la afirmación de la superioridad del pueblo de los fieles («Vision simplificatrice des groupes marginaux par le groupe dominant dans I'Espagne des XVIe et XVIle siècles» en A. REDONDO (comp.), Les problèmes de l'exclusion en Espagne (XVIe-XVIIe siècles), Publ. de la Sorbonne, Paris, 1983, p. 16).

41. S. DE TAPIA, La comunidad..., epígrafes "La actitud de los eclesiásticos hacia los moriscos" y "Manifestaciones de normalidad en las relaciones Concejo-convertidos", pp. 272-275 y 279-282 respectivamente. 
ellos a la viuda Gracia López y a su familia; como los miembros de esta familia se negaron a pagar fueron detenidos por la Inquisición, y dice el inquisidor "cuando se prendieron se alborotó toda Avila y tuvieron y han tenido tanto negocio y favor cual nunca yo vi en negocio de inquisición. Son gente muy bien tratada y los hijos muy vestidos de seda y oro y olores costosos..." 42 . Resulta significativo que las muestras más claras de aceptación del cristianismo (encargar misas, dejar mandas para las cofradías...) las protagonizan individuos, sobre todo mujeres, pertenecientes a las familias más acomodadas, las mismas que mantenían las relaciones sociales y económicas más intensas con la sociedad cristiana.

3. En 1610-1611 ni Concejo, ni Cabildo catedralicio ni Obispo creen al principio que la orden de expulsión afecte a los convertidos. Además, cuando la orden se hace explícita los regidores y canónigos envían a la Corte un delegado para que interceda ante el Rey y ante el Consejo de Estado para que los convertidos de Avila sean excluidos ${ }^{43}$.

\section{TESTIMONIOS INDIVIDUALES}

1. Hay muchos ejemplos que denotan que había total confianza en la seriedad profesional de los moriscos. Por ejemplo, a la altura de 1609 los párrocos de la ciudad dan poder a un convertido para que les traiga desde Sevilla 22.000 reales en plata (adviértase que se trataba de una fortuna: equivalía al salario anual de unos 50 peones ${ }^{44}$.

2. Varios clérigos y caballeros testificaron en 1611 acerca de la sinceridad del cristianismo de numerosos moriscos. Tales testimonios en general no fueron eficaces ${ }^{45}$.

3. En 1579 el obispo establece que a los granadinos no se les dé de comulgar ${ }^{46}$. El hecho de que no se aluda a los convertidos permite deducir que en este aspecto los descendientes de los mudéjares eran tratados como el conjunto de los feligreses.

4. No es raro ver a cristianos viejos que ponen a sus hijos a aprender el oficio con un maestro morisco (cordonero, confitero...) ${ }^{47}$.

Una vez repasados testimonios tan diversos creo que -a pesar de la aparente contradicción entre unos y otros- se puede deducir que, bastantes

42. AHN, Inq. leg. 4.603, exped. 1.

43. S. DE TAPIA, La comunidad ..., epígrafes "La actitud del Obispo de Avila" y "Concejo y Cabildo catedralicio contra la expulsión de los convertidos", pp. 351-355.

44. AHPAv, Pr. 656, fol. 29.

45. Archivo Diocesano de Avila, estante 108/5/26. Los beneficiados de estos informes son moriscos de Avila, Arenas, Madrigal, Pajares, Fontiveros, Oropesa y Piedrahíta.

46. Archivo Parroquial de Santo Domingo (Avila), Libro de Cuentas, I, s.f.

47. AHPAv, Pr. 627, fol. 398 y Pr. 570, fol. 680 respectivamente. Ambos acontecen en 1603. 
décadas después de haberse bautizado -y formalmente integrado en la sociedad cristiana-, los convertidos castellanos tenían clara conciencia de:

- Constituir un grupo humano peculiar: el de los descendientes de los "nuevamente convertidos de moros".

- Ser percibidos por la mayoría cristianovieja como gente con "nota y flaqueza" y por ello situada en un grado inferior de la escala del privilegio; esto suponía que, independientemente de las situaciones personales, como grupo podían recibir un trato desigual.

- Ser distintos de los granadinos llegados en 1570; esta diferencia también era asumida por los cristianos viejos. De forma que el factor religioso no fue capaz de sobreponerse a otros elementos sociológicos que diferenciaban a los descendientes de los mudéjares castellanos y a los granadinos.

\section{CONCLUSIÓN}

Resulta una obviedad decir que los moriscos atribuían su "diferencia" al factor religioso. La gran cuestión es saber cómo evolucionó el sentimiento de los convertidos castellanos hacia el hecho religioso al comprobar sistemáticamente que en muchos ámbitos sociales tenían un reconocimiento personal, pero en otros se les discriminaba como grupo a causa de la desconfianza religiosa.

Ante esta situación les cabían tres opciones: Profundizar su fe islámica. Asumir la fe cristiana cada vez más sinceramente. Relativizar los asuntos religiosos, por ver en ellos la fuente de su "mácula" social.

Apoyándome en la abundante documentación consultada, y dejando claro que ésta siempre es incompleta, yo me inclino a pensar que para el sector más dinámico de la comunidad abulense -y probablemente para el resto del grupo- el componente religioso fue cada vez menos influyente en la vida de aquellos moriscos ocupando la primacía de sus preocupaciones la adquisición de riquezas ya que con ellas podrían comprar, si no el reconocimiento social, al menos el bienestar personal. Esta circunstancia explicaría algunos hechos contrastados:

- Ausencia en estas tierras de literatura aljamiada.

- Progresiva disminución del número de procesados por el Santo Oficio.

- Aumento de las manifestaciones de integración social y económica con la mayoría.

- El informe del obispo de Avila en 1611: se limita a decir que no son buenos cristianos sin hacer ninguna alusión a que se mantengan en sus prácticas "heréticas", tal como sistemáticamente se decía de ellos décadas atrás. 
Este informe del obispo refuerza mi convencimiento de que su religiosidad sería muy elemental, tanto la que se pudiera atribuir al islamismo subyacente que aún poseyeran como la procedente del cristianismo de apariencia en el se veían obligados a vivir como el resto de los fieles.

¿Y qué decir de los del resto de Castilla la Vieja? A falta de estudios monográficos, la información disponible permite adelantar que el nivel de integración social era menor al hallado en la ciudad de Avila, que la Inquisición continuó actuando hasta el final (aunque con intensidad decreciente), que hubo alguna literatura aljamiada y que la mayoría se exilió antes de ser obligados por el Decreto. Por tanto, queda abierta la posibilidad de que la situación de la comunidad de la ciudad de Avila fuera excepcional y, en consecuencia, no generalizable.

Para terminar presentaré un texto inédito que con gran expresividad nos presenta la indefinición que los mismos moriscos antiguos castellanos tenían respecto a sus propias señas de identidad. Se trata de la carta que el 30 de marzo de 1611 envía Antonio de Avila ${ }^{48}$, un convertido arevalense, desde San Juan de Luz (Francia), a un amigo suyo cristiano viejo que vive en Arévalo. Del contenido de la misiva se deduce que su autor huyó de la villa castellana hacia 1607 por estar acusado de hurto. La carta consta de tres folios de buena caligrafía escritos en perfecto castellano ${ }^{49}$. Advierte al principio que lo que dice es la verdad ya "que si otro [otra cosa] fuera, en tierra estoy de libertad, que pudiera decir otro [otra cosa]"50. He aquí algunas de las frases más significativas:

48. En 1594 la Inquisición de Valiadolid realizó un conocido y detallado censo de los moriscos del distrito (AHN, Inq. leg. 2.109, pieza 1; este censo ha sido descrito y comentado por J.P. LE FLEM, «Les morisques du nord-ouest de l'Espagne en 1594...», Mélanges de la Casa de Velázquez, I, 1967, pp. 223-245). En la relación de los de Arévalo aparece nuestro Antonio de Avila con 18 años, por tanto en 1611 tendría unos 34 años.

49. AHN, Inq. 3.205, exp. 1. El texto íntegro se incluye al final como Anexo. Ver, respecto al buen nivel de alfabetización de los moriscos castellanos, S. DE TAPIA, «Nivel de alfabetización en una ciudad castellana del siglo XVI: sectores sociales y grupos étnicos en Ávila», Studia Historica. Historia Moderna, Salamanca, VI, 1988, pp. 481-502.

50. La aspiración por "vivir en libertad" o "en tierra de libertad" era expresada por los moriscos habitualmente. En 1565 un morisco segoviano les comentaba a unos enviados del rey de Argel (eso creía él, pero en realidad eran los espías a los que se alude en la nota 14) que deseaba "salir deste captiverio"; y dos familas de moriscos de Valladolid añadían que querían marcharse a Argel "por vivir en livertad y por no estar sufriendo tantas molestias como los herejes de los inquisidores les hazían de cada día" (AHN, Inq. leg. 3.205-2; ver S. DE TAPIA, «Las redes comerciales...», p. 236). Más conocido es el canto a la libertad de pensamiento que Cervantes pone en boca del morisco Ricote: "Pasé a Italia, y llegué a Alemania, y allí me pareció que se podía vivir con más libertad, porque sus habitadores no miran en muchas delicadezas: cada uno vive como quiere, porque en la mayor parte della se vive con libertad de conciencia" (Don Quijote de la Mancha, $2^{a}$ parte, cap. LIV). Sobre esta cuestión ver F. MárQuez VILlanueva, «El morisco Ricote o la hispana razón de Estado», en Personajes y temas del Quijote, Taurus, Madrid, 1975, pp. 229-335. 
"Todo quanto e hecho y dicho mientras e bibido en ese lugar le juro por la salvazión de mi alma, así de fiestas como de otras cossas, assido con mui bueno y santo zelo en serbizio de Dios y de la Birxen Santissima del Rrosario a quien yo serbía mui de corazón sin duda de otra cossa y anque yo fuera moro, como algunos judíos ${ }^{51}$ pensaban, los moros la quieren y rreberenzia[n] tanto como los cristianos y más" ${ }^{\prime \prime 2}$.

"...prometo que todo quanto se a dicho contra esta nazión [España] a sido pasión y enoxo y por mexor dezir boluntad de Dios que nos a querido dibidir el sentimiento que yo tengo de mi patria y amigos..."

"Estado [sic] en Torrellas gran parte de mi avsenzia ${ }^{53}$ y después ocho messen [sic] en Francia en el puer [sic] de A[g]de, treynta leguas antes de Marsella, donde e bisto enbarcar beynte y cinco mill ombres del rreino de Aragón ${ }^{54}$ y dos mi[1] castellanos y de nenguno fui conbertido [sic] para yr a Túnez, antes deseaba mucho yr a Rroma y bolber a mi [patria ?] cansado de andar por tierras axenas".

"Bien e sabido que un bellaco de un fraile dixo en Arévalo que me abíabía [sic] bisto en Arxel, más ya no se ussa dezir verdades, Dios los guarde de enemigos de la Santa fe católica y a mí mencamine en su santo ser[vizio]".

"También dizen quel Gran Turco aze mui grande armada, no se sabe para do más de que los moriscos de España, particularmente los granadinos, andan con gran solizitud llebando muchos presentes al Gran Tur[co] y procurando azer las mentiras berdaderas, assí que pues dezían que no abía quien abisase de nenguna de las que se imaxinaban contra España yo con mui buen zelo abiso y digo questá mui a cuenta a Su Maxestad de sacar de rraíz los moris[cos] dese rreino dezendientes de moros, anque finxan ser buenos católicos son ypócritas, que de temor comen y beben y de los tales se pueden fiar menos los católicos".

Creo, por tanto, poder concluir diciendo que en el momento de la expulsión los moriscos castellanos descendientes de los mudéjares locales constituyen unos grupos humanos desorientados, carentes de unas señas de

51. Cuando los moriscos castellanos se querían referir despectivamente a algún cristiano viejo le calificaban de judio.

52. Se trata de una evidente exageración. L. Cardaillac resume las dos distintas actitudes de los moriscos hacia María: "Por una parte los intelectuales y los habitantes de las regiones muy islamizadas conservaron las creencias coránicas: veneraban a María, o más bien la defendían y creían en su virginidad. Por otra parte, aquéllos para los cuales el Islam no era ya más que la base de la tensión polémica entre las dos comunidades atacaban a la Virgen y su virginidad para oponerse a los cristianos" (op. cit., p. 258). El caso de nuestro morisco arevalense no se acomodaría a ninguno de estos supuestos pues parece tratarse de una devoción semejante a la de cualquier cristiano viejo del pueblo.

53. La presencia durante tres años de Antonio de Avila en Torrellas se explica porque en ese pueblo aragonés, fronterizo con la Corona de Castilla, había una colonia de moriscos de Arévalo y de Avila; entre ellos buscó refugio (cf. J. VALLEJO ZAMORA, "Los moriscos de Torrellas entre 1495-1610: consideraciones demográficas», Turiaso (Inst. Fernando el Católico, Zaragoza), VII, 1987, pp. 283-323). El contexto de esta presencia en tierras aragonesas se sitúa en mi articulo «Las redes comerciales...» (p. 237).

54. Estos datos y cifras son corroborados por H. LAPEYRE, Geografía de la España morisca, Diputac. Prov. de Valencia, 1986, pp. 121-126. 
identidad firmes, y que buscan su acomodo social, su nicho ecológico. En la configuración de la nueva personalidad van a intervenir factores religiosos, económicos y culturales así como el trato recibido por parte de la sociedad cristianovieja. El peso de cada uno de estos elementos no va a ser igual en todos los lugares, por lo que se producirían tantas situaciones -en lo que se refiere a la consistencia de la identidad islámica- como colectivos moriscos. Y sospecho que la expulsión tampoco fue un factor capaz de hacer desaparecer estas diferencias. A este respecto creo que hubo una relación directa entre alto nivel de integración social y permanencia en países cristianos (Francia e Italia) aunque esta elección se efectuaría a niveles familiares y no por la totalidad de los conjuntos de cada núcleo urbano.

\section{APÉNDICE DOCUMENTAL}

Carta de un morisco de Arévalo a un amigo cristiano viejo escrita desde el destierro en el sur de Francia.

AHN, Inquisición, 3.205, exped. 1.

Mui deseado y leal amigo Sabastián Rredondo como a buen amigo le quiero dar parte de mi avsencia y salud y tanbién por saber de la de buesa merçed y de la de la señora Mari Gutiérrez y de los demás amigos que me quieran azer merçed. Sabrá el Señor Sabastián Rredondo por ésta el discurso de mi larga avssençia cumplido por la boluntad de Dios Nuestro Señor ques el criador y rremediador de todas las cossas y el berdadero juez que juzga y juzgará los corazos [sic] por su secreto juizio mui diferente que los ombres del mundo que con sus barias opiniones y propósitos quieren ser juezes de las almas aziendo a los aflixidos rreos y ellos santos ezétera. Todo quanto e hecho y dicho mientras e bibido en ese lugar le juro por la salvazión de mi alma, así de fiestas como de otras cossas, assido con mui bueno y santo zelo en serbizio de Dios y de la Birxen Santissima del Rrosario a quien yo serbía mui de corazón sin duda de otra cossa y anque yo fuera moro, como algunos judíos pensaban, los moros la quieren y rreberenzia[n] tanto como los cristianos y más y assí es esta satisfazión para que buesa merçed y los demás crean ques assí, que si otro fuera en tierra estoi de libertad que pudiera dezir otro y assí si otro me ubiera suzedido muriera sustentando la berdad que yo sé mui bien que algunos traidores me procuraban per der [sic] y entre tantos malos fue Dios serbido que ubo uno bueno que me abisó y Dios, como buen señor, y la Birxen Santissina, que sabía el santo y buen zelo con que yo la serbía, me libraron de quatro años de prisión y de un cruel martilio, bendito sea la maxestad de Dios y sus grandes secretos que quando se a de cumplir su boluntad lor dena [sic] cómo El es serbido. Como se echa de ber por la perdizión de tantos ninos [sic] y muxeres ynozentes padeziendo tan grandes trabaxos tan sin culpa por aber aconsexado a su maxestad tan mal se a bi[s]to en España una de las cossas más espantables quen los rreino[s] del mundo sean bisto y assí creo como cren [sic] todas las naziones del mun[do] que xamás España berá buen día que zierto a mobido a muchaion [sic] passión no digo solas las naziones, más a las yerbas y piedras y más por ser un caso tan sin culpa que prometo que todo quanto se a dicho contra esta nazión a sido pasión y enoxo y por mexor dezir boluntad de Dios que nos a querido dibidir el sentimiento que yo tengo de mi patria y ami- 
gos como el señor Sabastián Rredondo ssiento mucho su avsenzia y anque entiendo no seré creído porque tienen por zierto que nos queríamos alzar con la tierra es burla y, si eso fuera así, yo fuera el que fuera de los primeros que lo supiera, juro por la salbazión de mi alma que a[n] sido todos enbuste[s] y mentiras del demonio para que nos perdamos nossotros y buesa merçed es como berá brebemente en el discurso del tienpo y en las aparencias que se ban trazando y creo que los ynozenten [sic] sin culpa están pidiendo justizia a Dios lo encamine como mejor sea todo para su santo servizio y a todos nos dé paz, a los unos y a los otros, para que acabemos esta triste bida que con tantos trabaxos padezemos. Estado [sic] en Torrellas gran parte de mi avsenzia y después ocho messen [sic] en Francia en el puer [sic] de A[g]de, treynta leguas antes de Marsella, donde e bisto enbarcar beynte y cinco mill ombres del rreino de Aragón y dos mi[l] castellanos y de nenguno fui conbertido [sic] para yr a Túnez, antes deseaba mucho yr a Rroma y bolber a mi [patria ?] cansado de andar por tierras axenas. En estos cuidados supe como mi xente estaba en San Juan de Lus y así estoi com ellos. Lo que puedo dezir de la Françia ques mui fértil de comidas y quatro bezes más xente quen España y questán mui contentos de quel rrei a echado tanta xente fuera por que dizen que aora es mui pequeña, son enemigos capitanes de los españoles, desean mucho la gerra contra España por la codizia del tessoro que sola a de perder y de tener tanto[s] y tan grandes ynimigos, particularmente los luteranos, que son muchos los de Françia, y si no fuera por la muerte del rrei, que tenía ziento y zincuenta mill ombres y ziento y zincuenta piezas de artillería, y muchos millones. También dizen quel Gran Turco aze mui grande armada, no se sabe para do más de que los moriscos de España, particularmente los granadinos, andan con gran solizitud llebando muchos presentes al Gran Tur[col y procurando azer las mentiras berdaderas, assí que pues dezían que no abía quien abisase de nenguna de las que se imaxinaban contra España yo con mui buen zelo abiso y digo questá mui a cuenta a Su Maxestad de sacar de rraíz los moris[cos] dese rreino dezendientes de moros, anque finxan ser buenos católicos son ypócritas, que de temor comen y beben y de los tales se pueden fiar menos los católicos. El señor Sabastián Rredondo me ará mui gran merçed de a Cristóbal Ser[r]ano le dar un grande abrazo de mi parte y al señor don Gome y al señor don Diego Ossorio y a los demás caballeros y amigos. Beso mil bezes las manos. [A] Juan de Arévalo, Benito Se[r]rano, Franzisco Ssedeño y otros muchos que por no ser prolixo no pongo sus nombres dará mis encomiendas y que no les pese de me aber acompañado en las fiestas de la Madre de Dios que tanto como ellos y más que otro[s] bellacos las [he] tenido en mi corazón. Bien e sabido que un bellaco de un fraile dixo en Arévalo que me abíabía [sic] bisto en Arxel, más ya no se ussa dezir verdades, Dios los guarde de enemigos de la Santa fe católica y a mí mencamine en su santo ser[vizio]. Buesa merçed mescriba dándome parte de lo que ai de nuebo después del urto delizenciado palomo con la estafeta. Lo que ubiere de nuebo escribiré a buesa merçed, lo presente es quel Duque de Saboya ba sobre Xinebra, es mui fuerte y tiene mui gran fabor. Dios guarde a buesa merçed con la companía muchos años. Fecha de marzo a 30, año 1611 años.

Su leal amigo de buesa merçed

Antonio de Abila 